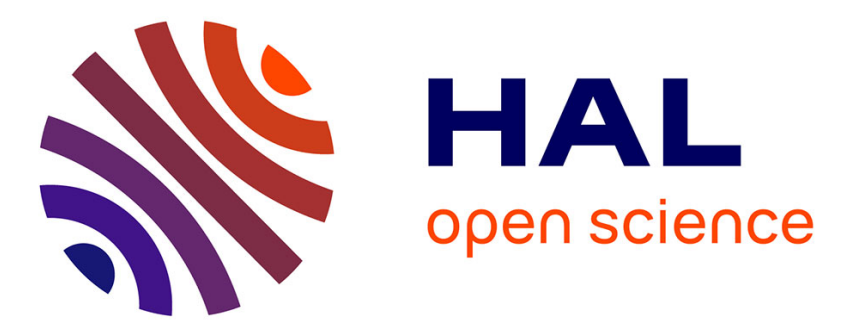

\title{
Optical microscopic observation of depletion layers, in a calamitic ferronematic lyomesophase
}

\author{
L. Liebert, A.M. Figueiredo Neto
}

\section{To cite this version:}

L. Liebert, A.M. Figueiredo Neto. Optical microscopic observation of depletion layers, in a calamitic ferronematic lyomesophase. Journal de Physique Lettres, 1984, 45 (4), pp.173-178. 10.1051/jphyslet:01984004504017300 . jpa-00232326

\section{HAL Id: jpa-00232326 https://hal.science/jpa-00232326}

Submitted on 1 Jan 1984

HAL is a multi-disciplinary open access archive for the deposit and dissemination of scientific research documents, whether they are published or not. The documents may come from teaching and research institutions in France or abroad, or from public or private research centers.
L'archive ouverte pluridisciplinaire HAL, est destinée au dépôt et à la diffusion de documents scientifiques de niveau recherche, publiés ou non, émanant des établissements d'enseignement et de recherche français ou étrangers, des laboratoires publics ou privés. 
Classification

Physics Abstracts

$61.30-14.82$

\title{
Optical microscopic observation of depletion layers, in a calamitic ferronematic lyomesophase
}

\author{
L. Liebert and A. M. Figueiredo Neto (*) \\ Laboratoire de Physique des Solides (**), Bât. 510, Université de Paris-Sud, 91405 Orsay, France
}

(Reçu le 6 octobre 1983, révisé le 6 décembre, accepté le 22 décembre 1983)

Résumé. - Des concentrations inhomogènes de grains magnétiques formant des couches de déplétion prévues théoriquement par Brochard et de Gennes ont été observées par microscopie optique dans les ferronématiques calamitiques lyotropes.

Ces couches de déplétion sont induites par des distorsions d'orientation du directeur formant des murs à l'intérieur desquels il est possible de visualiser les inhomogénéités de concentration des grains magnétiques.

\begin{abstract}
Inhomogenous magnetic grain concentrations giving depletion layers, theoretically predicted by Brochard and de Gennes were observed by optical microscopy in a calamitic ferronematic lyomesophase. These depletion layers were induced by orientation distortions inside walls where it is possible to visualize the inhomogenous concentration of magnetic grains.
\end{abstract}

\section{Introduction.}

Nematic lyomesophases are mixtures composed of amphiphilic compounds and water (with or without salt) $[1,2]$. Depending on whether the director orients parallel or perpendicular to the magnetic field $\mathbf{H}$, these mesophases have been classified [3] as type I and type II respectively. Depending on the form of the micelles, these lyomesophases are called [4] calamitic (prolate ellipsoidal micelles) or discotic (oblate ellipsoidal micelles). Evidences for a biaxial nematic have been recently reported $[5,6]$.

Nematic lyomesophases spontaneously orient $[1,3]$ in strong magnetic fields $(\mathbf{H})$. However, if a small quantity of a ferrofluid is dispersed in the mesophase, resulting in a lyotropic ferronematic, the magnetic field necessary to orient the sample is reduced by a factor of $10^{3}$ by comparison with that for the normal nematic mesophase [8].

These materials should have remarkable magnetic properties, as theoretically predicted by Brochard and de Gennes [8] for thermotropic ferronematic liquid crystals. They suggested the possibility of « depletion layers " for distorted situations when the condition of the major axis of the anisotropic magnetic grain [9] parallel to the director cannot be satisfied. In this case

$\left(^{*}\right)$ On leave from the « Instituto de Física, Universidade de São Paulo, CP : 20516 CEP : 05508 São Paulo (SP) Brazil » $\mathrm{CNP}_{\mathrm{q}}$ financial support.

$\left({ }^{* *}\right)$ Laboratoire associé au C.N.R.S. 
the grains are expected to migrate towards regions where the director is parallel to $\mathbf{H}$. This effect causes depletion layers.

In this letter, we report the first experimental observation of depletion layers in a calamitic ferronematic lyomesophase.

\section{Experimental.}

The nematic lyomesophase was prepared according to conventional procedures [4] with the following composition in weight $\%$ : potassium laurate $(28.33 \pm 0.06), 1$-decanol $(6.68 \pm 0.01)$ and water $(65.0 \pm 0.1)$. This mixture is a calamitic nematic at room temperature. A small quantity of ferrofluid $\left({ }^{1}\right)$ (magnetic colloid of magnetite anisotropic grains suspended in water of commercial origin : Ferrofluidics Corp.) was added to the nematic phase (about $0.050 \mathrm{wt} \%$ ). The components were mixed by stirring to form a stable blend at room temperature.

For the optical observations, samples were sealed in flat microslides from Vitro Dynamics Inc. with inside dimensions : thickness $100 \mu \mathrm{m} \times$ width $1 \mathrm{~mm} \times$ length $3 \mathrm{~cm}$. A polarized light microscope was used to observe the sample (orthoplan-Pol Leitz). The magnetic field (about $10 \mathrm{G}$ ) was obtained by Helmholtz coils or by small permanent magnets. All the observations were made at room temperature (about $24^{\circ} \mathrm{C}$ ) and the geometry of the experiment is presented in figure 1.

\section{Optical microscopic observations and discussion.}

The calamitic ferronematic lyomesophase in the presence of a magnetic field applied along the $X$ direction (Fig. 1) presented a planar texture after some hours. The mechanical coupling between the anisotropic magnetic grains and the nematic medium promoted the orientation of the prolate ellipsoidal micelles parallel to the major axes of the magnetic grains, i.e. parallel to $\mathbf{H}$ [8].

The surface orientational effect acts to place the long axes of the micelles parallel to the glass walls [10]. So when $\mathbf{H}$ is applied along the $X$ axis, only at the curved edges (See Fig. 1) of the microslide there is a competition between the magnetic field and the surface orientational effect. After some hours the defects observed principally at the edges of the microslide disappear. This fact indicates that the mechanical coupling between the magnetic grains and the micelles simulates the effect of a strong magnetic field.

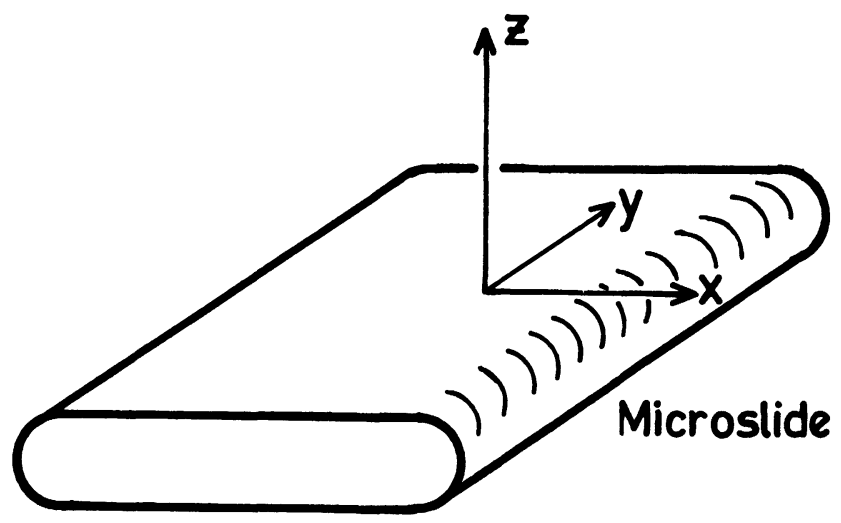

Fig. 1. - Definition of the $X, Y$ and $Z$ axes with reference to the microslide cell for the optical microscopy observations.

(1) Magnetization at saturation of $220 \mathrm{G} / \mathrm{cm}^{3}$, mean diameter $154 \AA$, standard distribution $94 \AA$, grains per $\mathrm{cm}^{3}: 1.9 \times 10^{16}$. 
Applying a magnetic field (created by Helmholtz coils) along the $Z$ direction in a previously planar oriented sample, a texture characterized by walls was obtained. These walls presented a continuous evolution. In this experimental condition, the ferrofluid grains (small needles) are oriented with their long axes parallel to the $Z$ direction and induced a planar to homeotropic transition.

Closed walls (Fig. 2) with a nearly ellipsoidal equilibrium form were observed. The long axes of the closed walls were oriented parallel to the $X$ axis. These walls were not stable. As the mechanical coupling remains, these closed walls tend to collapse. Within our accuracy, the eccentricity remains the same till the closed wall disappears. This phenomenon is usually observed in the planar to homeotropic transition for thermotropic liquid crystals [11].

Near the glass surfaces the micelles were oriented in the $X Y$ plane (surface anchoring effect) and in the bulk of the sample, the director tends to a homeotropic configuration (magnetic field

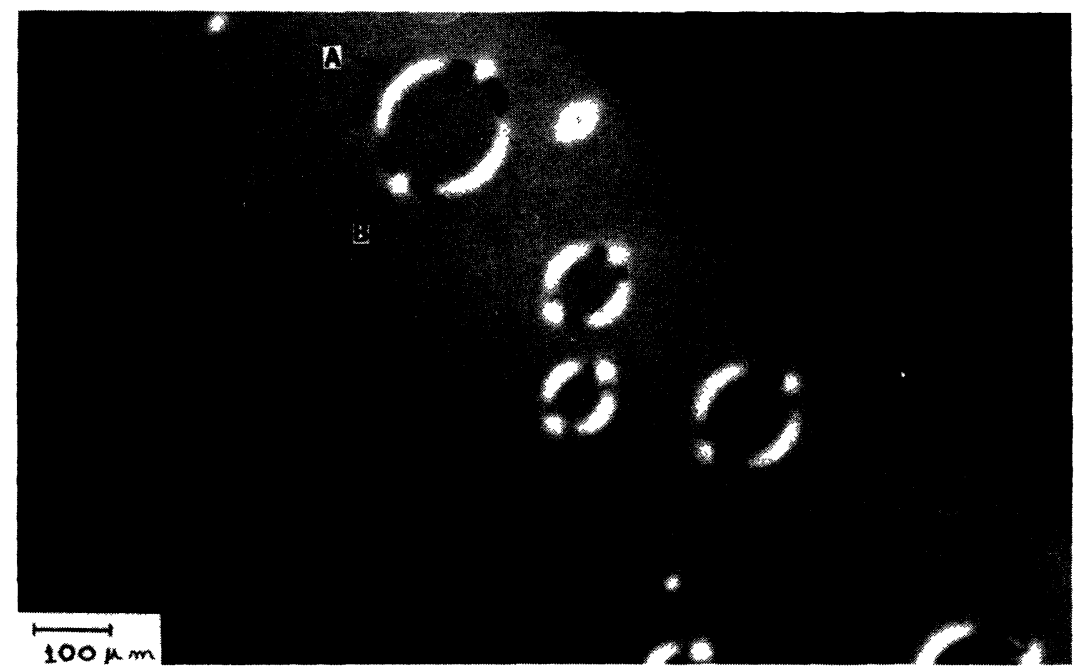

Fig. 2. - Closed walls obtained in a planar to homeotropic transition. Calamitic ferronematic lyomesophase of KL in a cell $100 \mu \mathrm{m}$ thick. Magnetic field along the $Z$ direction. Crossed polarizers.

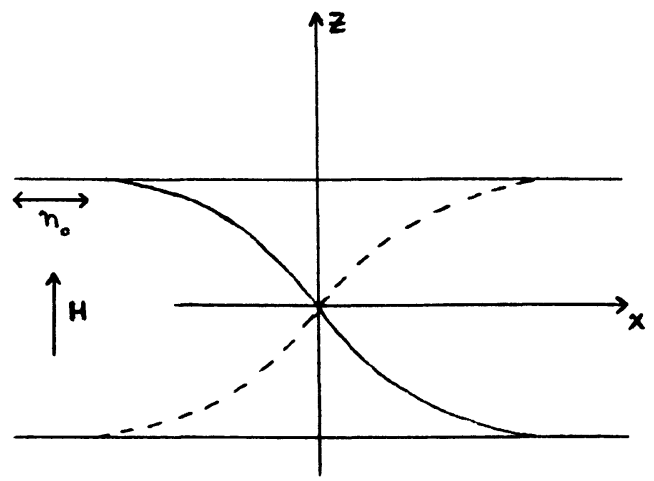

(a)

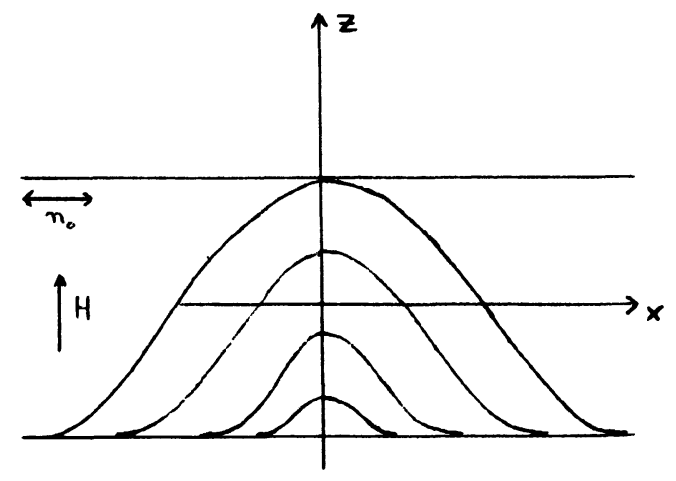

(b)

Fig. 3. - (a) Twist wall parallel to $\mathbf{H}$ [13]. (b) Splay/bend wall perpendicular to $\mathbf{H}$ [13]. 
(a)

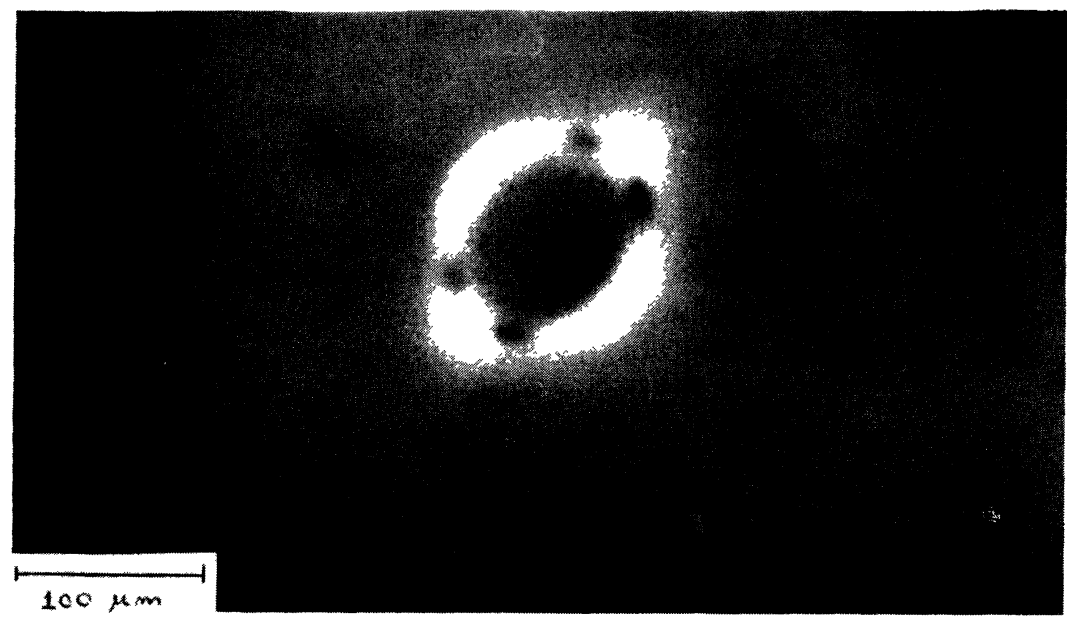

(b)

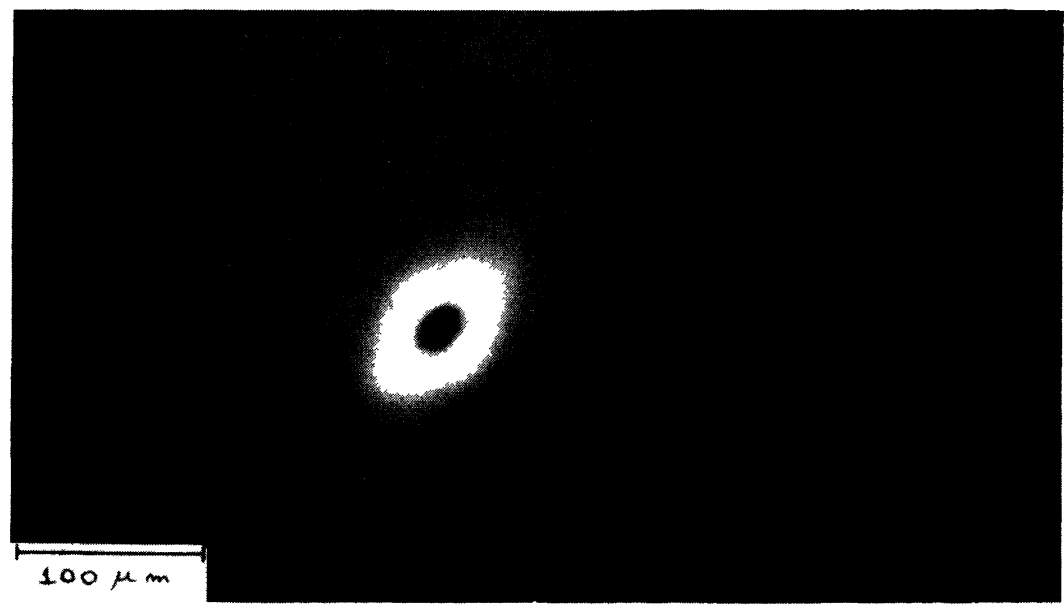

(c)

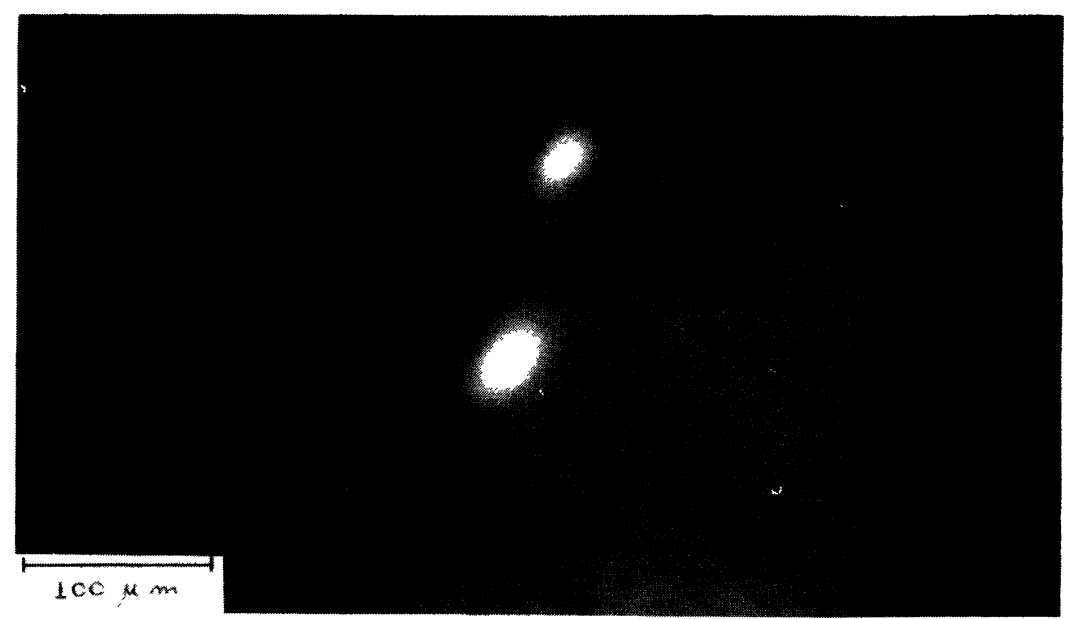

Fig. 4. - Same as figure 2. (a) $1: 30$ hours after the application of the field. Ferrofluid needles at the inside frontier of the closed wall. (b) 3 hours after the application of the field. Absence of ferrofluid needles in the region around the closed wall. (c) $4: 30$ hours after the application of the field. Nearly collapsed closed walls. 
action). In this experimental condition (which is equivalent to a Frederiks transition induced by a mechanical coupling), a twist wall [11-13] may be created parallel to the field.

Figure 2 shows the closed walls oriented with their long axes at $45^{\circ}$ to the polarization direction of the light beam.

The optical observations of these closed walls differ from those usually obtained with thermotropic liquid crystals [11-13].

We call $\mathbf{n}_{0}$ the micellar anchoring direction at the surfaces (parallel to the $X$ direction in our geometry) and $\mathbf{n}$ the local director. The long axes of the closed walls are parallel to $\mathbf{n}_{\mathbf{0}}$. The optical observation of both the regions inside and outside the closed walls indicates that $\mathbf{n}$ assumes the two allowed equally stable configurations (parallel and anti-parallel to $\mathbf{n}_{0}$ ) [13]. The region $\mathrm{A}$ (Fig. 2) of the closed wall can be interpreted as a twist wall parallel to the field (Fig. 3a). The region $\mathbf{B}$ (Fig. 2) can be interpreted as a splay/bend wall perpendicular to $\mathbf{H}$ (Fig. $3 \mathrm{~b}$ ). The four extinction regions observed in the closed walls (with crossed-polarizers configuration) cannot be explained by means of the geometries described in figure 3. A detailed description of them is the aim of a further paper [14]. The ferrofluid needles located inside the closed wall are confined inside the interior region of the wall. The wall (with the micelles not parallel to the magnetic grains) acts like a barrier which prevents the passage of the needles from the inside region to the outside [8]. As the closed walls tend to collapse, the magnetic grains are brought closely together (Fig. 4). As the needles are small permanent magnets arranged parallel to one another, there is a magnetic repulsion between them. So they are placed at the inside frontier of the closed wall and tend to prevent its complete collapse(Figs. 4a, b). At the end of the process (about 4 hours after the application of the field along the $Z$ direction), the closed wall nearly collapses and a point defect remains with all the magnetic needles confined in a small region (Fig. 4c).

As the magnetic grains are homogenously distributed in the sample, their number inside a closed wall depends uniquely on its initial dimension. If one observes the number of agglomerated needles inside the wall as a function of time, at the beginning of the process their number increases and after some time their number decreases. This fact can be understood as the agglomeration of small magnetic needles $(<1 \mu \mathrm{m})$ which are not visible when the first observations are made. As the needles grow further, they become visible and the agglomeration process continues till the end. In our experimental conditions, only grains bigger than $0.5 \mu \mathrm{m}$ could be observed.

In conclusion we observe some regions with a great concentration of ferrofluids and other regions without ferrofluids. The second regions are the depletion layers.

\section{Acknowledgments.}

We thank Dr. G. Durand for helpful discussions and Prof. Madhusudana for his help in revising the English presentation of the paper.

\section{References}

[1] Radley, K., Reeves, L. W. and Tracey, A. S., J. Phys. Chem. 80 (1976) 174.

[2] Forrest, B. J. and Reeves, L. W., Chem. Rev. 1 (1981) 1.

[3] Fujiwara, F., Reeves, L. W., Suzuki, M. and Vanin, J. A., in Solution Chemistry of Surfactants, ed. K. Mittal (Plenum Press, N.Y.) 1979, vol. 1, p. 63-77.

[4] Hendrikx, Y. and Charvolin, J., J. Physique 42 (1981) 1427.

[5] Yu, L. J. and SaUpe, A., Phys. Rev. Lett. 45 (1980) 1000.

[6] Bartolino, R., Chiaranza, T., Meuti, M. and Compagnoni, R., Phys. Rev. A 26 (1982) 1116.

[7] Liebert, L. et Martinet, A., J. Physique Lett. 40 (1979) L-363.

[8] Brochard, F. and DE Gennes, P. G., J. Physique 31 (1970) 691. 
[9] The magnetic grains have generally a spherical shape, however, they form anisotropic aggregates. See for example reference [7].

[10] Figueiredo Neto, A. M. and Amaral, L. Q., Acta Cryst. A 39 (1983) 651.

[11] Leger-Quercy, L., Thèse d'état. Faculté des Sciences d'Orsay, Université de Paris Sud (1976) and Mol. Cryst. Liq. Cryst. 24 (1973) 33-44.

[12] De Gennes, P. G., The Physics of Liquid Crystals (Oxford) 1974, p. 125-153.

[13] Brochard, F., J. Physique 33 (1972) 607.

[14] Figueiredo Neto, A. M. and Durand, G., to be published. 